\title{
Integrasi Telemedicine dengan Cloud Computing pada Web Pelayanan Kesehatan
}

\author{
Siti Alvi Sholikhatin', Adi Budi Prasetyo² \\ 1,2Informatika, Fakultas IImu Komputer, Universitas Amikom Purwokerto \\ e-mail: ${ }^{1}$ alvi.sholikhatin@gmail.com, ${ }^{2}$ adibudip81@gmail.com
}

\begin{abstract}
Abstrak
Era keterbukaan informasi serta kecepatan akses dan konektivitas memungkinkan masyarakat untuk mencari informasi dengan mudah tanpa batas jarak dan waktu. Kemudahan akses informasi bisa berdampak positif dan juga negatif. Tak terkecuali di bidang kesehatan dan pelayanan kesehatan lainnya. Tantangan terbesar salah satunya adalah terjadinya misinformasi karena masyarakat mendapatkan informasi terkait kesehatan dari sumber yang belum jelas kebenarannya. Tantangan lainnya yaitu semakin berkembangnya jenis-jenis penyakit dan diagnosa-diagnosa baru yang kemungkinan belum pernah ditemukan sebelumnya, keharusan bahwa antara penyintas dan paramedis harus berada di tempat dan waktu yang sama, serta kesulitan dalam mendapatkan akses layanan kesehatan yang memadai. Untuk mengatasi berbagai permasalahan tersebut, salah satu solusi yang dapat dikembangkan yaitu dengan membangun web telemedicine berbasis cloud. Penelitian ini kami lakukan di kota $\mathbf{X}$ dengan melakukan observasi terhadap beberapa klinik atau penyedia pelayanan kesehatan, serta melakukan serangkaian wawancara dengan masyarakat dari berbagai kalangan. Untuk memudahkan pengguna dalam mengakses web telemedicine ini, maka kami sediakan berbagai fitur antara lain: konsultasi langsung secara daring dengan dokter, mendapatkan resep untuk penyakit-penyakit ringan sehingga memudahkan pasien dalam mendapatkan obat di apotik terdekat, serta rekomendasi penanganan lanjutan ke rumah sakit untuk pasien yang membutuhkan tindakan penunjang. Web telemedicine ini mengutamakan kemudahan akses bagi pasien dan dapat digunakan dengan telepon pintar sehingga diharapkan web telemedicine dapat meningkatkan kesadaran masyarakat akan pentingnya mendapatkan layanan kesehatan yang terpercaya dan mudah dijangkau.
\end{abstract}

Kata Kunci: telemedicine, e-health, cloud computing

\begin{abstract}
The era of information system, speed of access and connectivity enables people to find information easily without distance and time limits. Easy access to information can have both positive and negative impacts. No exception in the field of health and services. One of the biggest challenges is the occurrence of misinformation because people get information related to health from sources whose truth is unclear. Other challenges include the development of new types of diseases and new diagnoses that may have never been found before, the necessity that between survivors and paramedics must be in the same place and time, as well as difficulties in getting access to adequate health services. To overcome these problems, one solution that can be developed is by building a cloud-based telemedicine web.

This research is conducted with thorough observation to several clinics, also we interviewed some citizens in the $X$ Town. To make it easier for user and for a convenience purposes, we have planned some features including: direct online consultation with doctors, getting prescriptions for minor ailments making it easier for patients to get medicine at the nearest pharmacy, as well as recommendations for continued treatment to the hospital for patients who need supportive medication. This telemedicine website prioritizes ease of access for patients and can be used with smartphone so that it is expected that the telemedicine web can increase public awareness of the importance of getting trusted and easily accessible health services.
\end{abstract}

Keywords: telemedicine, e-health, cloud computing 


\section{Pendahuluan}

Teknologi informasi dan komunikasi telah memasuki paradigma baru dan mempengaruhi semua aspek kehidupan, termasuk di bidang kesehatan. Dimana penemuan-penemuan dan alat-alat teknologi membantu tidak hanya pada proses pra-pelayanan, namun juga dalam pelayanan bahkan membantu menentukan diagnosa hingga layanan kesehatan jarak jauh sehingga pasien dan dokter tidak perlu bertatap muka. Tantangan terbesar layanan kesehatan di era milenial seperti sekarang antara lain: semakin berkembangnya jenisjenis penyakit dan diagnosa-diagnosa baru yang kemungkinan belum pernah ditemukan sebelumnya, keharusan bahwa antara penyintas dan paramedis harus berada di tempat dan waktu yang sama, serta kesulitan dalam mendapatkan akses layanan kesehatan yang memadai. Di bagian inilah teknologi informasi dan komunikasi berperan besar dalam mengatasi permasalahan. Teknologi informasi dan komunikasi menyediakan layanan yang mempermudah dan meningkatkan kualitas pelayanan kesehatan kepada masyarakat.

Salah satu teknologi di bidang kesehatan yaitu telemedicine. Telemedicine telah diperkenalkan sejak lebih dari 40 tahun yang lalu. Telemedicine adalah layanan kesehatan serta pertukaran informasi kesehatan yang dilakukan dari jarak jauh (Richard Wootton, 2017, hal. 2). Tujuan utama diciptakannya telemedicine adalah untuk menyediakan layanan medis berbasis ahli ke semua tempat yang membutuhkannya. Ada beberapa istilah yang sama dengan telemedicine: telecare yang berarti menyediakan perawatan kesehatan dan komunitas dukungan jarak jauh, telehealth yang berarti pelayanan kesehatan publik dimana penyintas ingin mendapatkan pelayanan kesehatan dari jarak jauh. Dari berbagai istilah tersebut, satu persamaan dengan telemedicine yaitu menyediakan pertukaran informasi tentang kesehatan tanpa mengharuskan penyintas dan paramedis untuk bertatap muka dan bertemu di satu tempat (Richard Wootton, 2017).

Telemedicine telah berkembang menjadi berbagai layanan aplikasi yang membantu penyintas mengetahui kondisi kesehatannya secara mandiri, serta membantu paramedis dalam memantau kesehatan pasien secara kontinyu. Layanan aplikasi tersebut antar lain: teleradiology, telesurgery, teleconsultation, remote patient monitoring, and health-care records management (Hung, 2003). Aplikasi-aplikasi tersebut bermanfaat untuk memberikan layanan yang mudah diakses oleh masyarakat yang membutuhkan informasi dan pelayanan kesehatan tanpa terbatas ruang dan waktu. Selain itu, aplikasi-aplikasi telemedicine tersebut juga sangat berguna bagi paramedis, terutama dokter, untuk memantau kondisi kesehatan penyintas yang dirawatnya, memudahkan komunikasi serta berbagi informasi dengan penyintas.

Berbagai macam bentuk telemedicine telah berkembang seiring dengan perkembangan teknologi. Seperti pengembangan telemedicine dengan WAPbased yang memanfaatkan telepon selular untuk menyediakan layanan kesehatan kepada penyintas, seperti konsultasi tekanan darah, konsultasi ritme denyut jantung serta membuat janji konsultasi langsung dengan dokter. Kemudian ada pula layanan telemedicine yang memanfaatkan teknologi animasi dan video untuk penanganan dini luka ringan, sehingga penyintas bisa dengan mandiri melakukan pertolongan pertama jika terjadi luka ringan. Video dan animasi telemedicine yang bersifat edukatif seperti ini sangat membantu penyintas sehingga tidak perlu pergi ke pusat kesehatan terutama ketika jarak antara tempat tinggal dan layanan kesehatan cukup jauh. Pada penelitian yang dilakukan oleh (Bryan L. Burke Jr, 2015, hal. 2) yang mengembangkan telemedicine untuk Dokter Spesialis Anak, yang terdiri dari teleeducation, teleconsultation, telepractice, dan telesearch.

Dalam paper ini, kami mengembangkan konsep aplikasi web telemedicine dan mengintegrasikannya dengan teknologi komputasi awan. Komputasi awan atau cloud computing adalah teknologi yang memanfaatkan internet dan menggunakan pusat server yang bersifat virtual untuk pemeliharaan data dan aplikasi (Christiani, 2018, hal. 11). Komputasi awan dipilih sebagai konfigurasi pelayanan web karena lebih mudah dalam penggunaan dan lebih ekonomis karena tidak memerlukan pembangunan infrastruktur secara mandiri. Layanan web ini diharapkan mampu membantu masyarakat kota $X$ dalam mendapatkan akses yang tepat dan cepat dalam mendapatkan informasi dan 
konsultasi kesehatan dengan ahli yang berkompeten.

Web telemedicine yang dikembangkan ini bertujuan untuk mengurangi tingkat disinformasi di masyarakat, khususnya pada masyarakat kota $\mathrm{X}$, meningkatkan kesadaran akan pentingnya menjaga kesehatan pada masyarakat, memudahkan pasien untuk berkonsultasi dengan dokter atau paramedis tentang kondisi atau keluhan kesehatan, memudahkan konsultasi daring dengan dokter, serta mengurangi antrian di klinik atau puskesmas karena masyarakat mendapatkan basic knowledge tentang bagaimana manangani keluhan atau penyakit-penyakit ringan seperti demam, influenza, sakit kepala, gatal-gatal, dan batuk.

\section{Metode Penelitian}

Metode penelitian yang digunakan yaitu deskriptif kualitatif. Peneliti mengamati bagaimana masyarakat kota $X$ cenderung untuk melakukan self-diagnose dengan hanya berdasarkan informasi yang didapat dari internet yang belum tentu terbukti kebenarannya. Ironi lainnya, mereka cenderung enggan untuk mendatangi dokter atau tenaga medis di klinik dan rumah sakit dengan berbagai alasan, salah satunya adalah masih rendahnya kesadaran akan pentingnya mendapatkan informasi dan layanan kesehatan dari orang atau pihak yang ahli di bidangnya.

Dari hasil wawancara dan observasi yang dilakukan kepada dua balai pengobatan atau klinik dan mengambil sampel acak terhadap warga di dua desa kota X, didapatkan kesimpulan bahwa hampir $60 \%$ dari mereka enggan untuk memeriksakan diri atau anggota keluarga jika sakit dengan alasan: jauh, hanya masuk angin, minum jamu saja, dan dogma yang begitu kental "nanti juga sembuh sendiri". Peneliti berusaha menangkap fenomena sosial yang terjadi di masyarakat kota $X$, dimana era keterbukaan informasi membuat sebagian masyarakat merasa bisa mengobati diri sendiri berdasarkan informasi-informasi yang didapat di internet. Dengan menggunakan metode penelitian kualitatif yang secara luas merupakan pendekatan yang interpretatif dan kritis pada masalah-masalah sosial, peneliti kualitatif berusaha menjangkau berbagai aspek di bidang sosial termasuk atmosfer yang membentuk suatu objek amatan yang sulit ditangkap melalui pengukuran yang presisif
(Somantri, 2005, hal. 60). Diharapkan dalam penelitian ini, implementasi telemedicine berbasis web yang terintegrasi dengan cloud dapat memberikan kemudahan kepada masyarakat dalam berkonsultasi dan mendapatkan informasi yang tepat dan akurat terkait masalah kesehatan.

Berikut adalah alur penelitian yang digunakan pada penelitian ini:

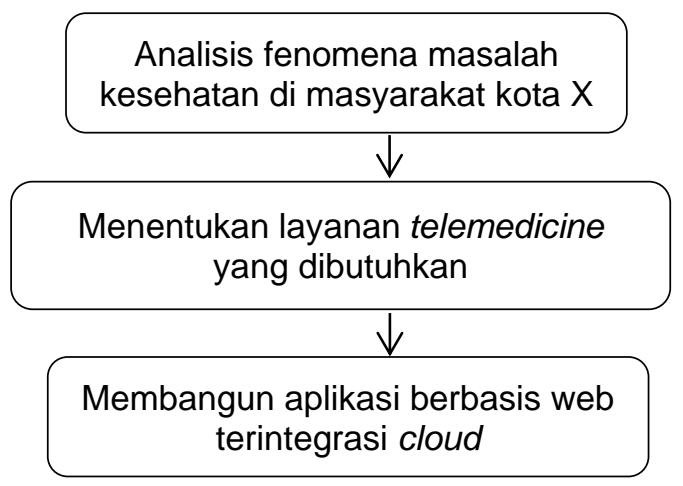

Gambar 1. Alur penelitian

1. Analisis fenomena masalah kesehatan di masyarakat

Berdasarkan wawancara secara acak yang dilakukan terhadap warga di dua desa di kota $\mathrm{X}$, disimpulkan bahwa warga cenderung untuk melakukan diagnosa mandiri ketika mengalami suatu masalah kesehatan. Berbekal telepon pintar dan aplikasi pencarian yang mudah digunakan, masyarakat bisa mendapatkan informasi yang mungkin belum jelas sumber dan masih diragukan kebenarannya.

2. Menentukan layanan telemedicine yang dibutuhkan

Dari analisis fenomena yang didapatkan, maka perlu adanya layanan daring berbasis web yang mudah digunakan dan diakses oleh masyarakat.

3. Membangun aplikasi berbasis web terintegrasi cloud

Layanan web yang dibangun ini diharapkan dapat membantu masyarakat dalam mendapatkan informasi dan berkonsultasi dengan dokter atau tenaga medis. Web telemedicine yang kami kembangkan juga merujuk pada penelitian (Rashid L. Bashshur, Gary W. Shannon, \& Brian R. Smith, 2014) yang mengembangkan telemedicine untuk memantau penyakit kronis antara lain: penyakit paru obstruktif kronis (PPOK), congestive heart failure, dan strok. Ketiga penyakit degeneratif tersebut bisa dikendalikan dampak buruknya bila 
dimonitor dan dipantau secara kontinyu dan seksama. Pemantauan menggunakan teknologi telemedicine untuk meminimalisasi faktor risiko, mengurangi cost pengobatan, serta meningkatkan angka harapan hidup penyintas.

\section{Hasil dan Pembahasan}

Berdasarkan hasil wawancara dengan sampel warga di dua desa yang terletak di Kota $X$ secara acak, didapatkan hasil yaitu hampir $60 \%$ dari mereka enggan untuk memeriksakan diri atau anggota keluarga jika sakit dengan alasan: jauh, hanya masuk angin, minum jamu saja, dan dogma yang begitu kental "nanti juga sembuh sendiri". Hasil ini menjadi permasalahan yang cukup serius ketika kelompok warga tersebut akhirnya mencari informasi sendiri terkait kesehatannya dan cara-cara penyembuhannya, yang belum tentu sumber tersebut bisa dipercaya dan berasal dari ahli yang berkompeten. Berawal dari akar masalah ini, peneliti mengajukan rancangan web telemedicine yang mudah diakses sehingga menjamin ketersediaan informasi kepada warga.

Layanan web telemedicine yang dirancang mencakup kemudahan kontak langsung secara daring dengan dokter mengenai keluhan atau gejala gangguan kesehatan ringan pasien. Telemedicine berbasis cloud ini memiliki menu anta lain: Profil pasien, Pilih Dokter Spesialis, Keluhan, Cetak Resep, Penanganan, dan Pengaturan. Menu langsung yang dapat diakses yaitu Lokasi Rumah Sakit, Chat Now, dan Penanganan Gejala. Profil Pasien berisi data pribadi pasien. Pilih Dokter Spesialis adalah menu untuk memilih dokter yang sesuai dengan keluhan atau gejala pasien yang diderita, misalnya Dokter Spesialis Penyakit Dalam untuk konsultasi mengenai gangguan lambung kronis. Menu Keluhan disediakan untuk pasien agar mengisi sesuai dengan gejala. Cetak Resep dilakukan ketika pasien sudah melakukan konsultasi daring denga dokter dan dokter memberikan resep agar pasien dapat menebus obat ke apotik terdekat. Penanganan digunakan ketika pasien membutuhkan penganganan lebih lanjut, yaitu berisi saran dari dokter yang bersangkutan. Pengaturan digunakan untuk melengkapi data pribadi pasien. Selengkapnya bisa dilihat pada Gambar 2. berikut ini.

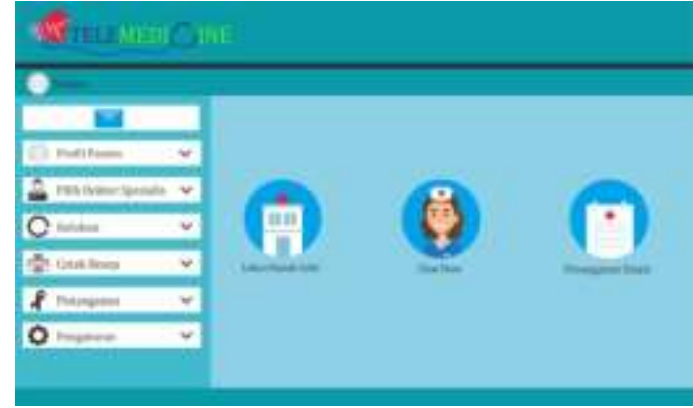

Gambar 2. Rancangan web telemedicine

Untuk dapat mengakses menu-menu tersebut, pasien harus melakukan login terlebih dahulu. Menu login dapat dilihat pada Gambar 3.

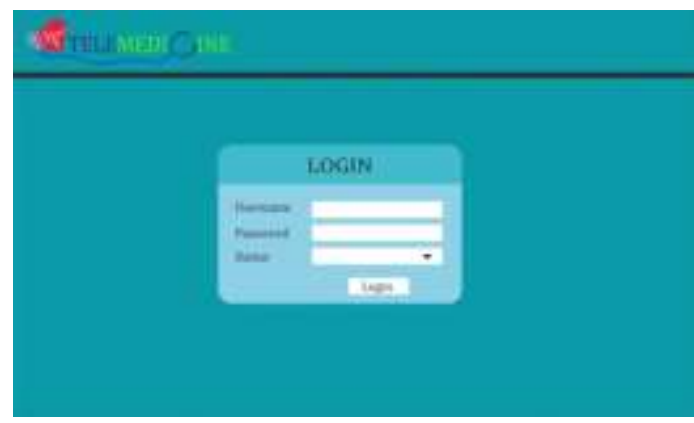

Gambar 3. Menu login pasien

Konsultasi langsung secara daring dengan dokter spesialis menggunakan menu Chat Now, merupakan layanan telemedicine yang memudahkan pasien dalam mendapatkan informasi mengenai penyakitnya dan langkah apa yang sebaiknya diambil. Web telemedicine ini digunakan untuk menangani keluhan dan penyakit yang tergolong ringan, seperti infeksi saluran pernafasan atas, demam, influenza, sakit kepala, gatal-gatal, dan batuk.

Konfigurasi infrastruktur telemedicine dengan teknologi komputasi awan memungkinkan kemudahan dalam integrasi data dan akses. Merujuk dari penelitian (Achmad Solichin, 2012) yang merancang arsitektur teknologi informasi yang berbasis cloud computing untuk perguruan tinggi di Indonesia, dimana sistem informasi akademik perguruan tinggi di Indonesia diintegrasikan menggunakan teknologi komputasi awan, sehingga memudahkan terjadinya data exchange antar perguruan tinggi, mengurangi redudancy sistem informasi serta menjaga standardisasi dan konsistensi data pada sistem informasi akademik setiap universitas. 
Infrastruktur web pelayanan kesehatan berbasis cloud ini bertujuan untuk meningkatkan efektifitas penggunaan web oleh masyarakat, mengurangi cost pengembangan web, serta meningkatkan integrasi dan keamanan data. Efektifitas cloud computing dalam mengurangi cost diperkuat oleh (Nuno Santos) yang mengatakan bahwa "Cloud computing infrastructures enable companies to cut costs by outsourcing computations ondemand" yang berarti dengan menggunakan infrastruktur atau teknologi cloud computing memungkinkan perusahaan atau organisasi memotong cost terutama untuk komputasi, dalam hal ini adalah storage atau penyimpanan.

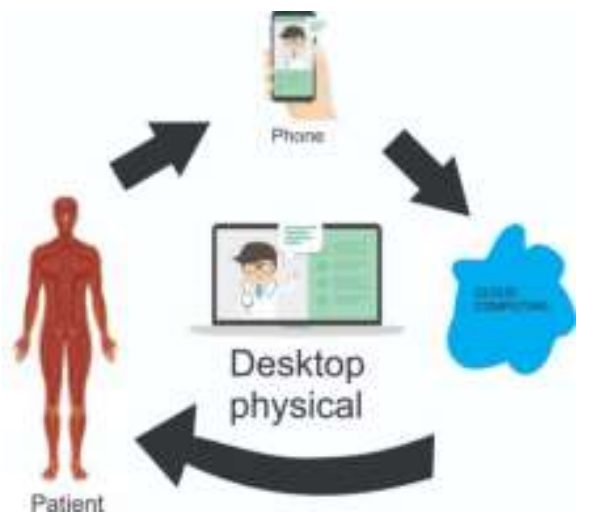

Gambar 4. Web telemedicine berbasis cloud

Gambar 4. menunjukkan bagaimana layanan web telemedicine ini bekerja. Web ini menyediakan informasi terkait penanganan dini penyakit-penyakit ringan yang masih mampu dilakukan pencegahan dan pengobatan mandiri. Pasien memilih akan berkonsultasi dengan dokter, menyatakan keluhan-keluhan yang dirasakan secara lugas dan jelas, kemudian dokter akan memberikan respon, rekomendasi, dan resep obat jika diperlukan pengobatan lebih lanjut. Pengobatan lebih lanjut dapat berupa online prescriptions dan rekomendasi untuk tindakan lanjutan di rumah sakit terdekat. Diharapkan dengan adanya web telemedicine ini, yang bisa diakses di semua platform, mampu memberikan kesadaran akan pentingnya kesehatan kepada masyarakat, serta memberikan informasi yang dapat dipertanggungjawabkan. Web ini dapat diakses dengan platform komputer desktop dan bisa juga diakses menggunakan telepon pintar. Kemudahan akses merupakan tujuan utama agar layanan telemedicine bisa menjangkau masyarakat luas.

Integrasi yang dilakukan dengan menggunakan cloud computing dapat dilihat pada Gambar 4.

\section{Web Telemedicine}

Akun e-mail (SaaS)

Akun Facebook (SaaS)

User 1

User 2

Gambar 5. Cloud-based Telemedicine

Layanan cloud computing yang digunakan untuk integrasi adalah dengan menggunakan akun e-mail atau akun media sosial pengguna yang akan masuk dan mengakses web telemedicine. Akun e-mail bisa berupa akun Yahoo mail, atau Google mail, sedangkan akun media sosial yang bisa digunakan yaitu akun Facebook. Ketiganya merupakan layangan cloud computing Software as a Service yang sudah digunakan secara luas oleh masyarakat.

\section{Kesimpulan}

Layanan web telemedicine berbasis cloud yang kami rancang merupakan solusi yang kami ajukan untuk mengatasi permasalahan di dua desa objek penelitian kami di Kota $X$, yang mana dari hasil observasi disimpulkan bahwa sebagian warganya masih enggan untuk berobat dan lebih memilih untuk mencari informasi pengobatan sendiri. Oleh karena itu, web kami diharapkan dapat membantu menangani masalah-masalah kesehatan yang ada di masyarakat, antara lain: selfdiagnose penyakit, keengganan masyarakat dalam berkonsultasi dengan dokter atau paramedis serta untuk membantu balai pengobatan atau klinik dalam meningkatkan awareness akan pentingnya menjaga kesehatan dan pencegahan penyakit yang benar. Lebih lanjut, telemedicine ini juga diharapkan dapat membantu masyarakat dalam mendapatkan informasi tentang kesehatan dan penanganan pertama penyakit ringan dari dokter dan paramedis yang kompeten, tanpa harus mengantri. Hal ini secara langsung juga mengurangi cost untuk pengobatan dan meningkatkan efisiensi waktu.

Beberapa aplikasi dan layanan telemedicine telah banyak dikembangkan 
oleh researcher di Indonesia bahkan dunia. Beragamnya rancangan telemedicine yang dibangun merupakan sinyal yang bagus agar kesadaran akan pentingnya akses kesehatan yang mudah dan efisien dapat dirasakan oleh semua kalangan. Bahkan ada pula layanan telemedicine yang secara khusus dibangun untuk memantau kondisi kesehatan pasien penderita penyakit tertentu, dengan memonitor kondisi tubuh pasien terkait dengan penyakit yang dideritanya.

Web telemedicine ini dibangun dengan mempertimbangkan kemudahan akses. Artinya, web dapat diakses melalui telepon pintar yang setiap orang sekarang sudah memilikinya. Namun demikian, ada kemungkinan beberapa kalangan masyarakat masih menemukan kesulitan dalam menggunakannya. Maka kami tidak menutup diri untuk terus memperbaiki kualitas web telemedicine untuk dapat digunakan oleh semakin banyak orang dan bersifat user-friendly. Pengembangan ke aplikasi yang lebih baik perlu terus kami perdalam agar web telemedicine dapat dimaksimalkan penggunaannya oleh masyarakat.

\section{Referensi}

Achmad Solichin, Z. A. (2012, 6). Pemodelan Arsitektur Teknologi Informasi Berbasis Cloud Computing Untuk Institusi Perguruan Tinggi Di Indonesia. Seminar Nasional Teknologi Informasi \& Komunikasi Terapan 2012, 7.
Bryan L. Burke Jr, M. F. (2015). Telemedicine: Pediatric Applications. The American Academy Of Pediatrics, 2.

C.S. Pattichis, E. K. (2002, April). Wireless Telemedicine Sytems; An Overview. Wireless Corner, 44, 11.

Christiani, L. (2018). Peluang dan Tantangan Penerapan Cloud Computing (Komputasi Awan) Sebagai Solusi Automasi Kerjasama Antar Perpustakaan. ANUVA, 2, 11.

Hung, K. (2003, June). Implementation of WAPBased Telemedicine Sytem for Patient Monitoring. IEEE Transactions On Information Technology In Biomedicine, 7, 7.

Nuno Santos, K. P. (t.thn.). Towards Trusted Cloud Computing.

Rashid L. Bashshur, P., Gary W. Shannon, P., \& Brian R. Smith, M. (2014, 9). The Empirical Foundations of Telemedicine Interventions for Chronic Disease Management. Telemedicine And EHealth, 20(9), 32.

Richard Wootton, J. C. (2017). Introduction to Telemedicine Second Edition. Florida, US: CRC Press.

Somantri, G. R. (2005, 12). Memahami Metode Kualitatif. Makara Sosial Humaniora, 9, 60.

Sudibyo Supardi, M. N. (2005, 8). Pengobatan Sendiri Sakit Kepala, Demam, Batuk Dan Pilek Pada Masyarakat Di Desa Ciwalen, Kecamatan Warungkondang, Kabupaten Cianjur, Jawa Barat. Majalah Ilmu Kefarmasian, 2, 11.

Wootton, R. (2001, 9). Telemedicine Recent Advances: Clinical Review. Centre for Online Health, 323, 4. 